\title{
LEY 388 DE 1997: UNA DÉCADA DE FORTALECIMIENTO LEGAL DEL ORDENAMIENTO ILEGAL.
}

\author{
Miguel Antonio Espinosa Rico ${ }^{1}$ \\ Grupo de Estudios Urbano-Regionales del Magdalena Medio. \\ Instituto Universitario de la Paz UNIPAZ.
}

Remisión artículo: 17-07-2007

Palabras Clave: Ordenamiento territorial, privatización, región alto Magdalena

Resumen: Hacer un balance de una década de funcionamiento de la Ley 388 de 1997, más conocida como Ley de Ordenamiento Territorial, resulta al mismo tiempo una tarea arriesgada pero atractiva, dado que para algunos resulta muy pronto para tal ejercicio cuando para otros es apenas justo. El presente artículo examina, desde la lectura de documentos oficiales y de la experiencia propia del autor, lo ocurrido en el departamento del Tolima entre los años 1997 y 2007 en relación a la aplicación de la citada Ley, concluyendo que la motivación, válida de la misma, ha sido objeto de la manipulación perversa de los propietarios de la tierra rural y urbana fortalecido la privatización del ordenamiento del territorio.

\section{Tres razones que soportan el ordenamiento territorial en Colombia}

La argumentación del Instituto Geográfico Agustín Codazzi IGAC (1997), para validar la Ley 388 de 1997 se condensa en tres razones:

1. El crecimiento desordenado, o no planificado de las ciudades.

2. El no funcionamiento de los centros urbanos como sistemas.

3. La segregación socioespacial generada en el interior de las ciudades.

Cada una de estas razones es objeto de argumentadas exposiciones de las cuales se deriva, en consecuencia, la necesidad imperiosa de asumir una actitud planificadora del territorio, éste si desde una perspectiva enteramente neoliberal:

1. Lograr una ciudad económicamente competitiva.

2. Lograr una ciudad socialmente equitativa.

3. Lograr una ciudad ambientalmente sostenible.

A diferencia de estos últimos tres preceptos bien podría haberse planteado que se buscaba generar un desarrollo urbano planificado; generar un espacio urbano sistémico y reducir la segregación socioespacial. Obviamente la connotación de la competitividad, la equidad y la sostenibilidad forman parte de la jerga impuesta por el modelo neoliberal en las políticas de reestructuración de los Estados Latinoamericanos y su uso es de obligatorio curso en la literatura oficial.

Claro resulta que el sistema urbano en los países dependientes está presionado a ajustarse de manera plena a los nuevos escenarios del mercado único global propuesto por el modelo neoliberal, lo cual explica la validez de la orientación hacia la competitividad del territorio. Allí

\footnotetext{
${ }^{1}$ Persona de contacto: correo electrónico: miguel.espinosa@unipaz.edu.co, miguelespinosa58@hotmail.com.
} 
está la esencia de la competitividad, no tanto como respuesta endógena de nuestras ciudades de frente al mercado global, sino como espacios de mercado de las grandes superficies y de los servicios financieros y de las tecnologías de la información y la comunicación (TIC), que succionan hasta la última gota los ingresos de los pobladores urbanos y de toda el área de influencia de las ciudades.

Así asistimos al espectacular tránsito de lo que es justo y sano, en términos de la filosofía liberal, a lo perverso, en términos de la nueva ideología y jerga neoliberal que comanda al sistema-mundo durante las últimas décadas.

\section{El estado de los planes de ordenamiento territorial en los municipios del Alto Magdalena}

Aunque parezca extraño, no se encuentran documentos de análisis sobre el estado del proceso de formulación de los esquemas y planes de ordenamiento territorial, al menos en los departamentos del Alto Magdalena, Tolima y Huila, Algunos ejercicios críticos se han realizado en diferentes momentos durante la última década, con el propósito de llamar la atención de las autoridades departamentales y municipales acerca del valor que los ejercicios de ordenamiento territorial pueden tener para la construcción de propuestas alternativas de construcción del territorio y de superación de problemas críticos del desarrollo local y regional.

Tan evidente es este aspecto que en la página del Ministerio del Medio Ambiente, Vivienda y Desarrollo Territorial, apenas aparece la información que aquí se trascribe en las tablas 1 y 2 , Tolima y Huila, respectivamente (ver también figuras 1 y 2). De dichas tablas se observa que mientras en el Huila los esquemas y planes de ordenamiento territorial fueron aprobados por los respectivos concejos municipales y autoridad ambiental entre los años 1999 y 2000, en estricto cumplimiento de los términos de la Ley, en el Tolima lo fueron entre los años 2000 a 2004 y 30 de los 47 lo fueron apenas entre los años 2002 a 2004.

Apenas en el año 2006 se logró el cumplimiento de la meta de formulación de esquemas y planes de ordenamiento territorial ${ }^{2}$; ya que el 6 de febrero, el municipio de Icononzo radicó ante la Corporación Autónoma del Tolima Cortolima, su esquema de ordenamiento territorial EOT, convirtiéndose en el último municipio del departamento (el número 47), en cumplir con la etapa de diagnóstico y formulación que amerita el proceso de ordenamiento del territorio.

No se cuenta un solo esquema o plan que a la fecha haya sido objeto de revisión y solamente el Plan de Ordenamiento de la capital del departamento se encuentra en dicho proceso, con carácter extraordinario, siete años después de ser aprobado. Paralelamente el municipio de El Espinal anuncia la iniciación del mismo proceso.

Para comprender la situación es necesario aclarar que en el caso del Tolima los esquemas y planes fueron asumidos por los municipios y el apoyo de entidades como del Departamento y la Corporación Autónoma Regional fue apenas un acto de voluntad verbal. En contraste, en el Huila tanto el Departamento como la Corporación Autónoma Regional del Alto Magdalena CAM, asumieron de frente y con recursos de sus presupuestos o por apoyo nacional el proceso, constituyendo una instancia de coordinación interinstitucional en la que participaron

\footnotetext{
${ }^{2}$ La Ley 388 de 1997, artículo 9, establece que los planes de ordenamiento del territorio se denominaran: a) Planes de ordenamiento territorial: elaborados y adoptados por las autoridades de los distritos y municipios con población superior a los 100.000 habitantes; b) Planes básicos de ordenamiento territorial: elaborados y adoptados por las autoridades de los municipios con población entre 30.000 y 100.000 habitantes, y c) Esquemas de ordenamiento territorial: elaborados y adoptados por las autoridades de los municipios con población inferior a los 30.000 habitantes.
} 
las entidades municipales, departamentales y la Corporación Autónoma Regional. Los resultados saltan a la vista.

En el mismo sentido, en el Tolima, con recursos del Fondo para la Reconstrucción Social y Económica del Eje Cafetero FOREC, se formularon los Lineamientos para el Ordenamiento Territorial Departamental (2000), sin que los mismos hayan sido considerados por los municipios o hayan tenido incidencia alguna en los procesos que en ese momento estaban en curso. La razón parece encontrarse en el hecho que tales lineamientos constituyen más bien la reedición de un convencional plan de desarrollo y no constituye una propuesta ordenadora para las dinámicas territoriales ni para la articulación de una política planificada de desarrollo local y regional.

En contraste, en el Huila la Asamblea Departamental expide la Ordenanza Número 78 de 2000, "Por la cual se adopta el Plan de Ordenamiento Territorial Departamental y se dictan otras disposiciones, acogiéndose a las atribuciones que le confiere el ordinal 2 del artículo 300 de la Constitución Política y el numeral 2 del artículo 7 de la Ley 388 de 1997".

Tabla 1 Tolima. Esquemas, Planes Básicos y de Ordenamiento Territorial

\begin{tabular}{|c|c|c|c|c|c|c|c|}
\hline No. & Municipio & Plan & $\begin{array}{l}\text { Adopt por } \\
\text { Acuerdo }\end{array}$ & $\begin{array}{c}\text { Resolución } \\
\text { CAR } \\
1390\end{array}$ & $\begin{array}{c}\text { Fecha } \\
\text { Resolución CAR } \\
29-S e n-00\end{array}$ & Fecha última & $\begin{array}{l}\text { Revisión y } \\
\text { ajuste } \\
\text { njursoso }\end{array}$ \\
\hline 1 & Ibagué & POT & & & & & En proceso \\
\hline 2 & Alpujarra & EOT & 1 & 266 & 03-Mar-04 & 7-Jul.04 & no \\
\hline 3 & Alvarado & EOT & 1 & 2260 & 12-Sep-03 & $06-A b r-04$ & no \\
\hline 4 & Ambalema & EOT & 1 & 232 & 01-Mar-04 & 20-Ago-04 & no \\
\hline 5 & Anzoátegui & EOT & 1 & 1946 & 14-Ago-03 & 20-May-04 & no \\
\hline 6 & Armero Guayabal & EOT & 1 & 267 & 03-Mar-04 & 13-Jul-04 & no \\
\hline 7 & Ataco & EOT & 1 & 1693 & 24-Jul-03 & 04-Mar-04 & no \\
\hline 8 & Cajamarca & EOT & 1 & 1579 & 03-Nov-00 & 04-Mar-04 & no \\
\hline 9 & Carmen de Apica & EOT & 1 & 1526 & 04-Jul-03 & 04-Mar-04 & no \\
\hline 10 & Casabianca & EOT & 1 & 428 & 29-Abr-04 & 20-Ago-04 & no \\
\hline 11 & Chaparral & РВOT & 1 & 1253 & 28-Sep-01 & 04-Mar-04 & no \\
\hline 12 & Coello & EOT & 1 & 850 & 21-Abr-03 & 15-Mar-04 & no \\
\hline 13 & Coyaima & EOT & 1 & 1217 & 20-Sep-01 & 04-Mar-04 & no \\
\hline 14 & Cunday & EOT & 1 & 551 & 14-Mar-03 & 04-Mar-04 & no \\
\hline 15 & Dolores & EOT & 1 & 2885 & 14-Nov-03 & 04-Mar-04 & no \\
\hline 16 & Espinal & РBOT & 1 & 1727 & 27-Nov-00 & 04-Mar-04 & no \\
\hline 17 & Falán & EOT & & 459 & 30-Abr-04 & 18-May-04 & no \\
\hline 18 & Flandes & EOT & 1 & 142 & 11-Feb-02 & 06-Abr-04 & no \\
\hline 19 & Fresno & РВOT & 1 & 1805 & 25-Nov-02 & 04-Mar-04 & no \\
\hline 20 & Guamo & РBOT & & 265 & 03-Mar-04 & 06-Abr-04 & no \\
\hline 21 & Herveo & EOT & & & & 04-Mar-04 & no \\
\hline 22 & Honda & EOT & 1 & 233 & 01-Mar-04 & 04-Mar-04 & no \\
\hline 23 & Icononzo & EOT & & & & 04-Mar-04 & no \\
\hline 24 & Lérida & EOT & 1 & 1569 & 09-Jul-03 & 04-Mar-04 & no \\
\hline 25 & Líbano & РВОТ & 1 & 610 & 16-May-01 & 04-Mar-04 & no \\
\hline 26 & Mariquita & РBOT & & 429 & 28-Abr-04 & 12-May-04 & no \\
\hline 27 & Melgar & EOT & 1 & 488 & 17-Abr-01 & 04-Mar-04 & no \\
\hline 28 & Murillo & EOT & 1 & 1864 & 08-Ago-03 & 04-Mar-04 & no \\
\hline
\end{tabular}




\begin{tabular}{|c|c|c|c|c|c|c|c|}
\hline 29 & Natagaima & $\overline{E O T}$ & 1 & 268 & 08-Mar-04 & 01-Oct-04 & $\overline{\text { no }}$ \\
\hline 30 & Ortega & РВOT & 1 & 1047 & 09-Ago-01 & 04-Mar-04 & no \\
\hline 31 & Palocabildo & EOT & & & & 04-Mar-04 & no \\
\hline 32 & Piedras & EOT & 1 & 1931 & 27-Dic-00 & 04-Mar-04 & no \\
\hline 33 & Planadas & РВOT & 1 & 1833 & 05-Ago-03 & 12-May-04 & no \\
\hline 34 & Prado & EOT & 1 & 1284 & 09-Ago-02 & 04-Mar-04 & no \\
\hline 35 & Purificación & EOT & 1 & 1541 & 08-Nov-01 & 04-Mar-04 & no \\
\hline 36 & Rioblanco & РВОТ & 1 & 332 & 15-Mar-02 & 04-Mar-04 & no \\
\hline 37 & Roncesvalles & EOT & 1 & 1726 & 27-Nov-00 & 04-Mar-04 & no \\
\hline 38 & Rovira & EOT & 1 & 145 & 11-Feb-02 & 04-Mar-04 & no \\
\hline 39 & Saldaña & EOT & 1 & 82 & 30-Ene-02 & 04-Mar-04 & no \\
\hline 40 & San Antonio & EOT & 1 & 440 & 29-Abr-04 & 12-May-04 & no \\
\hline 41 & San Luis & EOT & 1 & 1036 & 08-Ago-01 & 04-Mar-04 & no \\
\hline 42 & Santa Isabel & EOT & 1 & 2547 & 03-Oct-03 & 11-Mar-04 & no \\
\hline 43 & Suárez & EOT & 1 & 604 & 19-Mar-03 & 04-Mar-04 & no \\
\hline 44 & Valle de San Jua & EOT & 1 & 146 & 11-Feb-02 & 04-Mar-04 & no \\
\hline 45 & Venadillo & EOT & 1 & 482 & 06-May-04 & 21-Jun-04 & no \\
\hline 46 & Villahermosa & EOT & 1 & 795 & 06-Jun-00 & 04-Mar-04 & no \\
\hline 47 & Villarica & EOT & 1 & 2934 & 21-Nov-03 & 10-Mar-04 & no \\
\hline 47 & Total Tolima & & 41 & & & & no \\
\hline
\end{tabular}

Fuente: Ministerio de Ambiente Vivienda y Desarrollo Territorial MAVDT, 2004. 
Tabla 2 Huila. Esquemas, Planes Básicos y Planes de Ordenamiento Territorial

\begin{tabular}{|c|c|c|c|c|c|c|c|}
\hline No. & Municipio & $\begin{array}{l}\text { Tipo } \\
\text { de } \\
\text { Plan }\end{array}$ & $\begin{array}{c}\text { Adoptado } \\
\text { por } \\
\text { Acuerdo } \\
\text { o } \\
\text { Decreto } \\
\text { Municipal }\end{array}$ & $\begin{array}{l}\text { Resolución } \\
\text { CAR }\end{array}$ & $\begin{array}{c}\text { Fecha } \\
\text { Resolución } \\
\text { CAR }\end{array}$ & $\begin{array}{l}\text { Fecha última } \\
\text { Actualización }\end{array}$ & $\begin{array}{c}\text { Proceso de } \\
\text { Revisión y } \\
\text { ajuste }\end{array}$ \\
\hline 1 & Neiva & РОТ & 1 & 548 & 9--jun-00 & 01-Dic-03 & $\begin{array}{c}\text { concertación } \\
\text { con la CAM }\end{array}$ \\
\hline 2 & Acevedo & EOT & 1 & 659 & 05-Jul-00 & 01-Dic-03 & En proceso \\
\hline 3 & Agrado & EOT & 1 & 481 & 23-May-01 & 01-Dic-03 & No \\
\hline 4 & Aipe & EOT & 1 & 114 & 07-Feb-00 & 01-Dic-03 & En proceso \\
\hline 5 & Algeciras & EOT & 1 & 1393 & 20-Dic-00 & 01-Dic-03 & No \\
\hline 6 & Altamira & EOT & 1 & 604 & 22-May-00 & 01-Dic-03 & no \\
\hline 7 & Baraya & EOT & 1 & 1147 & 27-Oct-00 & 01-Dic-03 & no \\
\hline 8 & Campoalegre & EOT & 1 & 1396 & 10-Dic-99 & 01-Dic-03 & Concluido \\
\hline 9 & Colombia & EOT & 1 & 18 & 11-Ene-00 & 01-Dic-03 & no \\
\hline 10 & Elías & EOT & 1 & 1463 & 27-Dic-99 & 01-Dic-03 & no \\
\hline 11 & Garzón & РBOT & 1 & 1438 & 22-Dic-99 & 01-Dic-03 & En proceso \\
\hline 12 & Gigante & EOT & 1 & 1332 & 05-Dic-00 & 01-Dic-03 & En proceso \\
\hline 13 & Guadalupe & EOT & 1 & 543 & 09-Jun-00 & 01-Dic-03 & En proceso \\
\hline 14 & Hobo & EOT & 1 & 19 & 11-Ene-00 & 01-Dic-03 & no \\
\hline 15 & Íquira & EOT & 1 & 126 & 11-Feb-00 & 01-Dic-03 & no \\
\hline 16 & Isnos & EOT & 1 & 125 & $12-F e b-00$ & 01-Dic-03 & no \\
\hline 17 & La Argentina & EOT & 1 & 1366 & 14-Dic-00 & 01-Dic-03 & no \\
\hline 18 & La Plata & РBOT & 1 & 345 & 06-Abr-00 & 01-Dic-03 & Concluido \\
\hline 19 & Nátaga & EOT & 1 & 344 & 06-Abr-00 & 01-Dic-03 & no \\
\hline 20 & Oporapa & EOT & 1 & 133 & 14-Feb-00 & 01-Dic-03 & no \\
\hline 21 & Paicol & EOT & 1 & 129 & $11-F e b-00$ & 01-Dic-03 & \\
\hline 22 & Palermo & EOT & 1 & 1427 & 21-Dic-99 & 01-Dic-03 & Concluido \\
\hline 23 & Palestina & EOT & 1 & 127 & $11-F e b-00$ & 01-Dic-03 & no \\
\hline 24 & Pital & EOT & 1 & 1459 & 27-Dic-99 & 01-Dic-03 & no \\
\hline 25 & Pitalito & РBOT & 1 & 100 & 01-Feb-00 & 01-Dic-03 & Concluido \\
\hline 26 & Rivera & EOT & 1 & 1366 & 06-Dic-99 & 01-Dic-03 & Rivera \\
\hline 27 & Saladoblanco & EOT & 1 & 113 & 07-Feb-00 & 01-Dic-03 & no \\
\hline 28 & San Agustín & EOT & 1 & 130 & 11-Feb-00 & 01-Dic-03 & no \\
\hline 29 & Santa María & EOT & 1 & 530 & 02-Jun-00 & 01-Dic-03 & En proceso \\
\hline 30 & Suaza & EOT & 1 & 1228 & 02-Jun-00 & 01-Dic-03 & Concluido \\
\hline 31 & Tarqui & EOT & 1 & 94 & 31-Ene-01 & 01-Dic-03 & no \\
\hline 32 & Tesalia & EOT & 1 & & $\sin$ & 01-Dic-03 & no \\
\hline 33 & Tello & EOT & 1 & 213 & 02-Mar-00 & 01-Dic-03 & no \\
\hline 34 & Teruel & EOT & 1 & 529 & 02-Jun-00 & 01-Dic-03 & no \\
\hline 35 & Timaná & EOT & 1 & 1349 & 30-Nov-99 & 01-Dic-03 & no \\
\hline 36 & Villavieja & EOT & 1 & 1416 & 22-Dic-00 & 01-Dic-03 & no \\
\hline 37 & Yaguará & EOT & 1 & 53 & 17-Ene-00 & 01-Dic-03 & En proceso \\
\hline 37 & Total Huila & & 37 & & & & \\
\hline
\end{tabular}

Fuente: Ministerio de Ambiente Vivienda y Desarrollo Territorial MAVDT, 2004. 
Figura 1 Mapa Tolima. Localización de los Planes, Planes Básicos y Esquemas de Ordenamiento Territorial

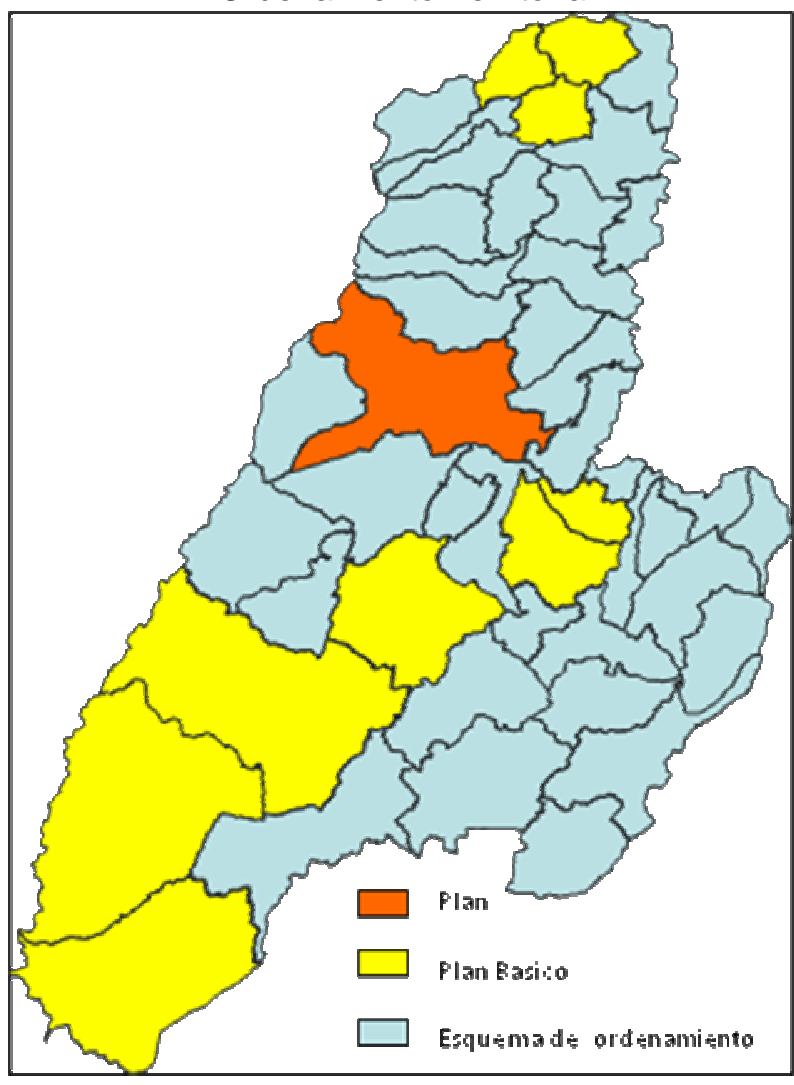

Fuente: Elaboración propia

El texto de la Ordenanza, si bien se expide en el momento en que se está concluyendo la aprobación de los esquemas y planes, ha sido fruto del trabajo de coordinación de esfuerzos técnico-políticos entre el Departamento Administrativo de Planeación Departamental y la Asamblea. El contenido de la Ordenanza es por supuesto muy superior en su concepción, orientaciones y formulación a los inadvertidos Lineamientos para el Ordenamiento Territorial del Tolima. 
Figura 2 Mapa Huila. Localización de los Planes, Planes Básicos y Esquemas de Ordenamiento Territorial

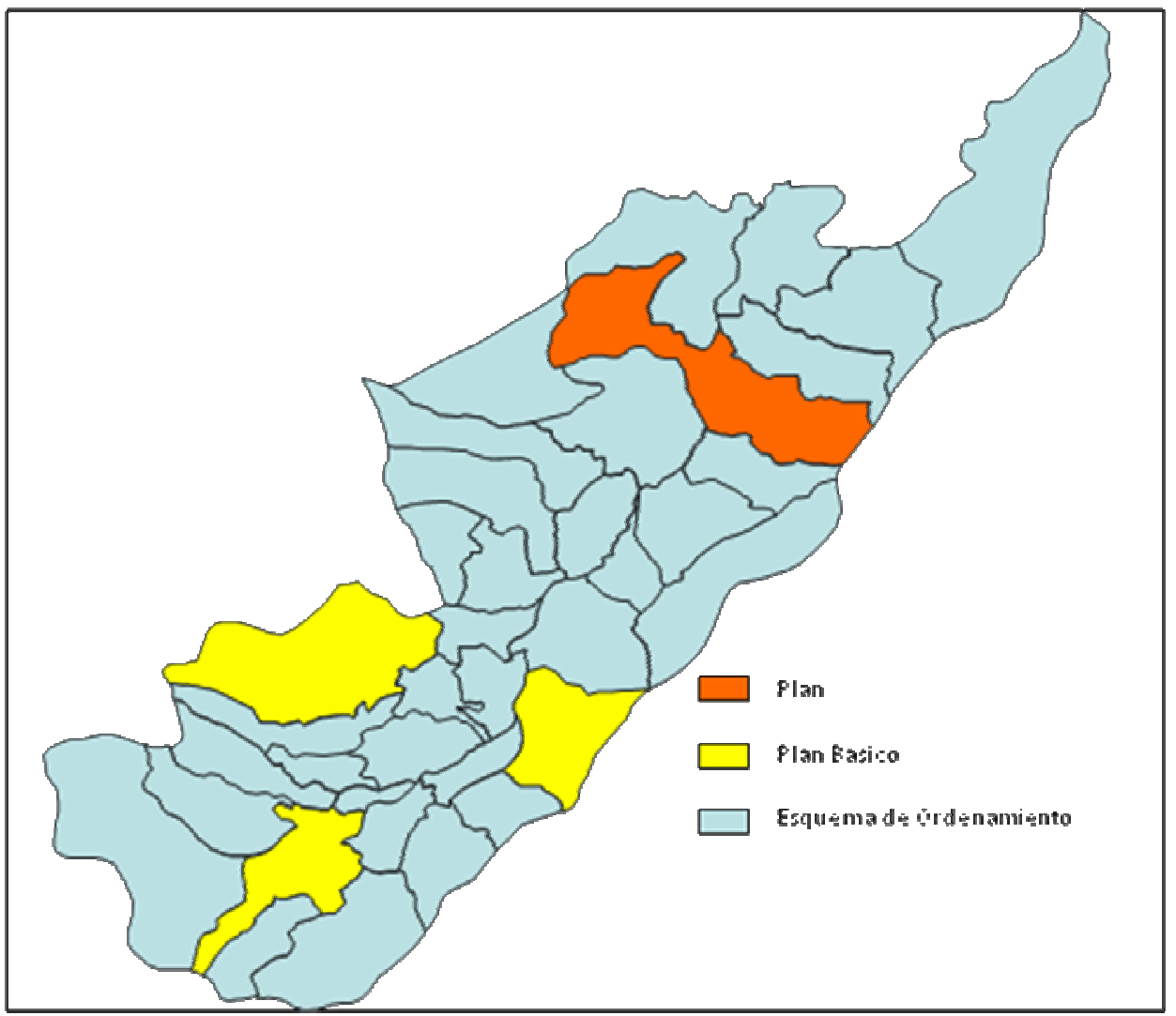

Fuente: Elaboración propia

En el informe de gestión 2005 de la Corporación Autónoma Regional del Alto Magdalena CAM, se lee:

Durante la vigencia 2005, vale resaltar la articulación de esfuerzos y acciones entre el Gobierno Departamental y la Autoridad Ambiental Regional, con miras a ofrecer a las Administraciones Municipales un acompañamiento coordinado, sistemático y planificado en todos los procesos de gestión e implementación de sus POT.

De la misma manera se logró un fortalecimiento de la participación social, comunitaria, gremial e institucional en los procesos de revisión, modificación y ajuste de POT, así como en los de formulación de Planes Parciales ${ }^{3}$.

En el caso del Tolima nunca este tipo de coordinación interinstitucional fue posible, a pesar que se realizaron numerosas reuniones entre la Corporación Autónoma, la Gobernación, la Universidad del Tolima, el IGAC y otras entidades privadas interesadas.

En el informe financiero y de gestión 2004, de la Contraloría departamental del Huila, se analizan los cuatro ejes del Plan de Desarrollo del gobierno departamental de la vigencia concluida, uno de los cuales es el correspondiente a ordenamiento territorial, ambiente e infraestructura, que muestra una visión integral del desarrollo territorial y que ha sido objeto del

\footnotetext{
${ }^{3}$ Corporación Autónoma Regional del Alto Magdalena. Recuperado 10 de julio de 2007. 
trabajo de las administraciones departamentales de los períodos 2001-2003 y 2004-2007. De dicho eje se lee en la evaluación en mención:

ORDENAMIENTO TERRITORIAL, AMBIENTE E INFRAESTRUCTURA: Cuyo objetivo es alcanzar una infraestructura acorde a los lineamientos del Plan de Ordenamiento Territorial del Departamento [en adelante POTD], y adecuada para propiciar un desarrollo sostenible y competitivo, conforme al espacio físico y a las oportunidades de mercado. Se han formulado siete estrategias básicas, dirigidas a mejorar la cobertura y prestación de los servicios públicos como el gas domiciliario, agua potable y saneamiento básico, telecomunicaciones y energía eléctrica; además, se prevé el mejoramiento de la red vial secundaria, el desarrollo de proyectos de infraestructura eléctrica, el incremento de la competitividad de todo tipo de transporte para pasajeros y carga y la gestión de recursos para la conservación del equilibrio ecológico del Macizo Colombiano y otras áreas protegidas y ecoturísticas.

Los recursos asignados a este Eje temático representan el $21.9 \%$ del total del cuatrienio. Referente a la fuente de financiación de este Eje Temático, los mayores recursos provienen de la Nación con el $40.5 \%$, seguida por el Departamento con el $32.4 \%$, los municipios con el $6.7 \%$ y las otras fuentes tienen asignado el $20.4 \%$ del total.

Sin duda el mayor impacto del proceso iniciado en el departamento del Huila tiene que ver con la conformación de una alianza estratégica entre el Departamento, la CAM, los municipios, el IGAC, las universidades públicas y privadas y otras entidades públicas y privadas, cuyo propósito central estaba orientado a lograr una adecuada asesoría y acompañamiento a las entidades territoriales municipales para el proceso de formulación de los esquemas y planes de ordenamiento territorial, lo cual se ve reflejado en el Plan de Ordenamiento Territorial Departamental, ya comentado atrás.

Sin embargo, conversaciones con funcionarios de la Dirección de Planeación Departamental y CAM del Huila ${ }^{4}$, permiten constatar que el proceso ha sido afectado por la acusada debilidad de las entidades territoriales municipales en aspectos como la capacidad técnica, la inexistencia de expedientes municipales y la discontinuidad en las políticas de los gobiernos municipales. A ello se agrega el hecho que la Ley 388 constituye una orden de nivel nacional que delega en los departamentos una función de asistencia técnica que no está acompañada por mecanismos de acción frente a los municipios. En esta misma perspectiva se hace evidente la pérdida del papel articulador del Departamento con respecto a las políticas del desarrollo territorial, las cuales quedan prácticamente al libre albedrío político y la capacidad financiera que logre cada municipio.

Los mayores logros en materia de aplicación del POT se percibe y constata en la ciudad de Neiva, donde a partir de 1997 se promueve una notable transformación del espacio urbano y de la relación de la ciudad con los municipios del departamento. Un artículo del periódico La Nación ${ }^{5}$, en su edición de celebración de sus 10 años de publicación, destaca los cambios más notables en la ciudad entre 1994 y 2004. Indica el artículo:

Hace 10 años, Neiva era una ciudad relativamente pequeña, a partir de ese momento, las grandes construcciones y la descentralización urbanística y comercial, empezaron a surgir. Desde 1994 Neiva en materia urbanística ha cambiado considerablemente, en los últimos años nuestra ciudad dio un vuelco a nivel de ordenamiento territorial, a raíz de la

\footnotetext{
${ }^{4}$ Comunicación con Elena Borrero, funcionaria del Departamento Administrativo de Planeación del Huila y Hernán Cortés, profesional de la Corporación Autónoma Regional Alto Magdalena CAM 17 de junio de 2007

${ }^{5}$ Polanía, J. Periódico La Nación. Recuperado 14 de junio de 2004.

http://www.lanacion.com.co/cms/index.php?option=com_content\&task=blogcategory\&id=77\&ltemid=89\&yearlD=2004\& monthID=6\&day ID $=15$
} 
Constitución Nacional de 1991 y posteriormente en el año 1997 con la Ley 388, los municipios y en particular Neiva, empezaron a ordenar el territorio y a definir políticas y estrategias para mejorar la estructura urbana de la ciudad y disminuir los desequilibrios urbanos que existen en el aspecto normativo.

En 1994, Neiva no poseía edificaciones atractivas y novedosas. Los centros comerciales, de diversión, restaurantes, auditorios, edificios oficiales y privados entre otros, se ubicaban en su gran mayoría, en el centro de la ciudad. Arquitectónicamente, las edificaciones no eran novedosas y modernas, además con la contaminación visual, no se podía casi distinguir una de la otra.

Indica el artículo que el POT permitió orientar el desarrollo urbano regional alrededor de ejes estratégicos como:

- Red hídrica, como eje estructurante del espacio público urbano;

- Equipamientos urbanos de impacto regional;

- Orientación de la localización de infraestructura privada y los desarrollos urbanísticos;

- Definición de la malla vial en sus escalas local y de articulación regional

Adicionalmente, con posterioridad a 2004 se han formulado varios planes parciales, cuya orientación guarda los lineamientos del POT y propone una interesante propuesta de diseño de los espacios urbanos, siendo a primera vista superior a lo observado en ciudades intermedias como Ibagué, Armenia, Pereira, donde se ha formulado planes parciales.

Con respecto a los procesos de revisión el resultado es alentador si se lo comparara con lo observado en el Tolima, donde de 47 municipios tan solo Ibagué se encuentra adelantando el proceso de revisión y ajuste. De los 37 municipios del Huila, 5 ya realizaron el proceso y 9 están adelantándolo. En los restantes 23 municipios el proceso enfrenta dificultades debidas a la carencia de recursos para su financiación.

En este mismo departamento, el Huila, la Corporación Autónoma destinó recursos al apoyo y asesoría a los tres municipios mayores del departamento. Igualmente se cuenta con un aplicativo instalado en cada municipio, para la formulación de los expedientes municipales, el cual fue posible con recursos aportados por el Departamento y el concurso de la CAR. La necesidad de la revisión y ajuste de los POT en el departamento se ha hecho evidente ante la exigencia del cumplimiento de normas o políticas por parte de entidades nacionales, departamentales o incluso locales. En el espacio urbano la exigencia de licencia para emisiones de residuos líquidos o sólidos que generan conflictos de uso, la presencia de mataderos, entre otros, obligan la referencia a la necesidad de la revisión y ajuste.

En fin, igual que lo ocurrido con la exigencia de la formulación de los esquemas y planes, con posterioridad a la presentación de éstos, la actitud y el comportamiento de las municipalidades es similar y se espera algún tipo de presión externo para asumir la tarea.

\section{Los departamentos: La difícil situación en un modelo centralista y altamente ejecutivo}

Con la Ley 388 de 1997 ocurrió como en el dicho popular de que No hay que darle carne al que no tiene dientes, pues es obvio que entidades departamentales como el Tolima, no lograron asimilar que la Ley podría constituir una herramienta oportuna para generar espacios de coordinación entre el nivel local y el departamental, perdidos con la reducción de las funciones de las reformadas y casi extinguidas secretarías de planeación departamental. 
Al ya criticado hecho de inexistencia de una Ley Orgánica de Ordenamiento siguió la advertencia de un proceso de ordenamiento municipal sin la previa definición de una política departamental, agravado con las deficiencias en recursos financieros para la formulación de los esquemas y planes, pero más grave aún, con la implementación de ejercicios que no pudieron contar con los medios tecnológicos para la producción de la cartografía municipal. Con excepciones, el país no cuenta con mapas departamentales que puedan ser configurados a partir de las cartas municipales y ni siquiera pudo comprenderse la verdadera función de recursos tecnológicos como los de Diseño Asistido por Computador (conocido por sus siglas en ingles como CAD Computer Aided Desing), o los Sistemas de Información Geográfica SIG.

Toda la cartografía municipal en el Tolima, como lo sería en la mayoría de departamentos, fue editada en CAD, herramienta construida para labores de ingeniería y arquitectura pero no para la producción cartográfica, la cual tiene niveles de exigencia ya reglados internacionalmente.

Con todo, una adecuada comprensión de la ocasión brindada por el proceso de formulación de los esquemas y planes de ordenamiento territorial se dejó escapar por parte de muchos departamentos. Allí estaba la oportunidad de formalizar procesos provinciales y de establecer apuestas estratégicas de desarrollo territorial, buscando rescatar el papel del Departamento en la coordinación de las políticas de desarrollo local y en el puente necesario entre el nivel local y el departamental y entre éstos y el nivel central de gobierno. La llamativa visión urbanoregional en esquemas y planes de ordenamiento territorial no pasa de ser un ejercicio interesante aportado por los asesores y consultores, pero cae en el vacío porque no se encuentra anclada a proceso alguno de escala regional. Como muchos aspectos de la documentación presentada, hace parte de los requisitos de obligatoria presentación exigidos por quienes tenían a su cargo la revisión y concepto del informe final, pero solo eso.

La excusa, en buena medida válida, de la ausencia de recursos para implementar un dispositivo técnico apropiado para la administración del proceso de ordenamiento del territorio, ha resultado en que a partir de 2004 ni las corporaciones autónomas ni los departamentos administrativos de planeación ni las contralorías departamentales, volvieron a constituir instancias de presión sobre los debidos procesos de revisión y ajuste de los POT, y mucho menos que los programas de gobierno y los planes de desarrollo se vieran obligados a tomar éstos como referentes para su formulación.

En el Tolima la división de ordenamiento territorial de la Corporación Autónoma lleva un trabajo ingente durante de tres años, tratando de normalizar el mapa departamental, a partir de la cartografía producida por los diferentes esquemas y planes de ordenamiento territorial en un tránsito de CAD a un Sistema de Información Geográfica SIG, que a su vez demandará un proceso de verificación y ajustes en campo.

En síntesis, no se dispone aún, diez años después de implantada la Ley 388, de un mapa departamental y toda cartografía que se produce y existe en la actualidad es, necesariamente, objeto de duda técnica.

La Ley 388 en su carácter municipalista y en cierta medida autista del desarrollo, llegó a escenarios departamentales despojados, por las reformas estructurales del Estado, de competencias soportadas en medidas de política nacional, para ejercer un papel de orientación explícita de su aplicación y de mecanismos de obligatoriedad aplicables a las municipalidades. En suma, se configuró un cuadro de reforzamiento del centralismo, restándole capacidad real tanto a los municipios, los mayores afectados, como a los departamentos, heridos de muerte por las leyes $550^{6}$ y $617^{7}$.

\footnotetext{
${ }^{6}$ Aunque las empresas fueron las que más aprovecharon la Ley 550, un total de 74 entes territoriales, entre los cuales figuran municipios y departamentos, acudieron a ese instrumento para saldar sus deudas. Al respecto, Gilberto Toro, presidente de la Federación Colombiana de Municipios, señaló que "las leyes 550 y 617 sí funcionaron, pese a que fue
} 


\section{La utilidad del ordenamiento en los procesos urbanos de las grandes y medianas ciudades}

Ordenar para controlar más eficientemente las relaciones de poder y hacer más evidentes los procesos de segregación socioespacial, parece ser un resultado cierto de la introducción de la normatividad derivada de la obligatoriedad de contar con el POT en las ciudades.

En el caso de ciudades como Ibagué, la orientación de los usos del suelo, la delimitación del perímetro urbano y de las áreas de expansión, han sido sugeridas por los equipos de profesionales vinculados al sector de la construcción y del urbanismo.

Inclusión y exclusión inexplicadas de áreas en el perímetro urbano y erráticas medidas con relación a la vocación de los usos del suelo y de las áreas de expansión, han marcado el traumático proceso de formulación del POT y la actual revisión del mismo, siete años después de su aprobación y cuatro después de haberse cumplido el plazo de su primera revisión.

La inclusión y exclusión han obedecido en todo caso al poder de presión que los propietarios han tenido sobre el gobierno municipal, confirmando el principio según el cual en el régimen capitalista, el capital, es el instrumento ordenador del territorio y constructor de espacios de valor. La validez de la teoría del valor y la renta del suelo de Marx son aquí irrefutables y se aplican con la crudeza que solo es posible esperar del capitalismo y de los capitalistas.

El ordenamiento territorial lejos de lograr la reducción de las desigualdades socioespaciales del desarrollo, es decir, la equidad social y la reducción de la segregación socioespacial, refuerza la construcción de ghetos exclusivos bajo las figuras cuestionadas de conjuntos cerrados y sectores exclusivos bajo el cuidado oficial y la vigilancia compartida de la fuerza pública y verdaderos ejércitos armados privados.

También, como en el caso concreto de lbagué, existen quebradas que al entrar y salir de predios donde se han construido conjuntos cerrados, han sido cercadas, es decir, incorporadas de manera a todas luces ilegal, a la propiedad privada de los mismos.

El fortalecimiento de la segregación socioespacial se hace visible en la orden de definir las áreas para la llamada vivienda de interés social VIS, reforzada por medidas privadas, avaladas por la política gubernamental, de destinar ciertos sectores de las ciudades a vivienda para estratos socioeconómicos superiores. Al hacerlo así, las clases altas garantizan que alrededor de sus conjuntos exclusivos no se aproximen los pobres, a los cuales por lo demás han ido expulsando discretamente de la vecindad a punta de medidas silenciosamente agresivas de especulación en el precio de la tierra y en la elevación inconsulta del estrato socioeconómico en los cobros de servicios públicos.

muy duro para muchos alcaldes por los grandes sacrificios sociales y políticos que debieron asumir". Recuperado 14 de abril de 2008. http://www.elpais.com.co/paisonline/ediciones_anteriores/ediciones.php?p=/historico/abr142008/PRI

${ }^{7}$ Según Gutiérrez (Diputado del Departamentos de Caldas) "Además de la nueva categorización de departamentos y municipios, la Ley contempla un plan de racionalización de las finanzas públicas locales que pone en peligro la existencia de más de 400 municipios del país y de no pocos departamentos, si al cabo de cuatro años no logran «viabilizar» sus entidades. Se determina, de igual manera, la eliminación de personerías, contralorías, institutos del deporte, consejerías para la mujer, la niñez y la juventud, oficinas para la atención de vivienda de interés social, defensa del medio ambiente, quejas y reclamos, dependencias de tránsito, casas de la cultura, veedurías y hasta las funciones de control interno y contabilidad se podrán prestar por entidades afines en los municipios de categorías dos a seis. En los demás municipios se deberán reducir a lo mínimo. Y para completar el desorden en el manejo de la cosa pública, a partir de la expedición de la Ley no se exigen calidades profesionales o técnicas a los directivos o secretarios de despacho de los municipios de la tercera a sexta categoría". Recuperado Abril 15, 2008, de http://www.deslinde.org.co/Dsl41/Dsl41_indice.html 
El afán por hacer más vivible la ciudad se vuelve una frase vacía, cuando se observa que lo que interesa ordenar es fundamentalmente los mecanismos propicios para la realización de la óptima renta de la tierra, combinando propuestas dirigidas, por un lado, a sectores con medianos y altos ingresos y; por otro, a sectores pobres, a los que se envía a ocupar las periferias urbanas socioeconómicamente marginalizadas.

Los sectores de medianos y altos ingresos se ubican en enclaves urbanos bajo la figura de conjuntos cerrados, con localizaciones que van desde espacios geográficamente centrales de la malla urbana hasta periferias de alto valor construido por la alta inversión en su amoblamiento, accesos y construcción arquitectónica.

Los sectores de bajos ingresos se ubican en las periferias urbanas, empujando justamente los perímetros urbanos hasta el límite con las áreas de futura expansión. Todo muy bien concebido para hacer posible también la futura expansión de las redes de servicios y dejando servido el enriquecimiento de los propietarios de tierras en los cinturones de expansión urbana.

La Ley 388, como instrumento legal, ha cumplido como todos los dispositivos de información, un papel crucial desde la apropiación que de la misma han hecho quienes desde la posesión de la tierra urbana y del capital financiero la han hecho funcional a sus intereses, no sin contar con el papel favorable de las administraciones municipales. Así, el ordenamiento ha sido fundamentalmente diseñado desde arriba y los ejercicios de la participación ciudadana se han reducido apenas a los actos formales de aprobación de las medidas tomadas por la vía de los listados de asistencia a los eventos públicos convocados para formalizar, de manera indebida, decisiones que no son compartidas por toda la ciudadanía.

Es decir, la información sobre el proceso de ordenamiento territorial si ha permitido realizar diagnósticos incluso inéditos sobre la realidad territorial municipal y procesos de formulación de usos del suelo que en muchos casos han sido los apropiados a la aptitud de los mismos y a la conveniencia colectiva. Sin embargo, es en la aplicación que la conveniencia colectiva ha sido reemplazada por la conveniencia particular y la orden de cómo planificar los usos del suelo ha servido solo para fortalecer los procesos de realización particular de la renta del suelo, haciendo uno perverso de la información servida por el POT.

Por citar solo un ejemplo, todos, o la mayoría de los esquemas y planes de ordenamiento territorial han recomendado la densificación urbana para presionar la construcción sobre predios $^{8}$ vacíos o lotes de engorde presentes en el espacio urbano, pero también los urbanizadores han recurrido a estrategias de urbanización sobre sectores marginales de los actuales perímetros urbanos, con lo que por un lado aparecen acogiendo la medida pero por otro, elevan exponencialmente la valorización de los lotes que se siguen reservando en espacios urbanos centrales.

En el Plan de Ordenamiento Territorial de Ibagué (2000), se lee:

La vivienda contribuye con el $59 \%$ de los ingresos prediales, lo que desde el punto de vista de la tributación hace más atractiva una política de consolidación del área urbana del municipio, y no de expansión, porque por un lado se tiene la infraestructura de servicios públicos y hace más viable él llevarlos hasta el perímetro de la ciudad, y por el otro, la presencia de lotes sin urbanizar no contribuye en mayor grado a los ingresos prediales, ya que sólo representan el 27\%, y generan un crecimiento desordenado de la ciudad (subrayado nuestro).

\footnotetext{
${ }^{8}$ Según el artículo 11 de la Resolución 2555 de 1998, emitida por el IGAC, un predio es "el inmueble perteneciente a una persona natural o jurídica, o a una comunidad situado en un mismo municipio y no separado por otro predio público o privado".
} 
El comportamiento histórico de los recaudos prediales evidencia una tendencia fluctuante: Los años de mayores recaudos se deben a políticas de incentivos tributarios y no a la generación de rentas. En el año 1998 la notable caída de los recaudos está inducida por la situación general de la economía del país. En lo que se refiere a su participación en el total de ingresos del municipio muestra una tendencia estable, lo que hace necesario optar por la generación de nuevos prediales.

Del área urbana, aproximadamente el $44 \%$ está para ser urbanizada, en términos económicos y a la luz de la ley 388, este hecho le representa al municipio y a los particulares, un mayor valor agregado, generado por la normativa y la implementación de proyectos de impacto económico y social. Desde la óptica de la tierra como tal, adquiere un mayor valor ese $40 \%$ del territorio, que en este momento tiene un valor catastral de aproximadamente $\$ 1.500 .000$ millones de pesos, y generará como mínimo un 30\% adicional, de los cuales, el municipio recauda entre el $30 \%$ y $40 \%, \$ 67.500$ millones de pesos, lo que equivale al déficit presupuestal actual de la administración central municipal (91-92)

La figura 3 ilustra el caso de la ciudad de Ibagué, donde a partir de la entrada en vigencia de la Ley 388 de 1997, todos los proyectos de Vivienda de Interés Social VIS, se han localizado, y se continúan localizando, en la periferia urbana, en las comunas $6,7,8,9,12$ y 13 . Allí mismo se ilustra como los conjuntos exclusivos, destinados a estratos 4,5 y 6 se localizan en lotes de engorde de las comunas geográficamente centrales: 3, 4, 5 y 6 .

Es conocido por los equipos de formulación, hace siete años, y de revisión, en la actualidad, que en Ibagué, una ciudad con medio millón de habitantes, según el Censo del Departamento Administrativo Nacional de Estadística DANE $2005^{9}$, se dispone de un poco más de 1.400 hectáreas de suelos de expansión urbana proyectada, frente a solo 1.600 hectáreas para Bogotá, con una población cercana a los siete millones de habitantes. Allí queda en evidencia cómo y hacia qué sectores apunta la mirada el uso especulativo de la renta de la tierra en esta ciudad colombiana, replicando una práctica que ha sido oficialmente protegida por décadas de la historia urbana.

Con respecto a procesos que ofrecen alta potencialidad en la planificación del desarrollo urbano, como los planes parciales, Laserna (citado por Giraldo, 2006, pág.13), expresa:

... la falta de adecuada concepción de los planes parciales, han hecho que estos instrumentos lejos de ser aplicados como mecanismos impulsores de desarrollos urbanísticos integrales a través de la reglamentación urbanística específica para secciones de la ciudad completos o autosuficientes, se han convertido simplemente en un trámite previo y adicional al ya tradicionalmente utilizado de la obtención de la correspondiente licencia de urbanización.

En efecto, los planes parciales, a diferencia del propuesto para la Comuna 7 de Barrancabermeja ${ }^{10}$, han sido propuestos por sectores privados vinculados a la construcción 0 por instancias de planeación municipal.

\footnotetext{
9 Consultado Departamento Administrativo Nacional de Estadística DANE. Recuperado 12 de junio, 2007, de http://190.25.231.242/cgibin/RpWebEngine.exe/PortalAction?\&MODE=MAIN\&BASE=CG2005BASICO\&MAIN=WebSer verMain.inl

${ }^{10}$ El Plan Parcial de Ordenamiento Territorial y Unidad de Gestión Urbanística Ciudadela Educativa de la Comuna 7 de Barrancabermeja, fue un proyecto propuesto por una organización comunitaria de base con el apoyo de la Corporación Desarrollo y Paz del Magdalena Medio CDPMM, la Empresa Colombiana de Petróleos Ecopetrol, Merilectrica S.A. y la Alcaldía de Barrancabermeja. El documento puede ser consultado en la Sede Paloka de la Corporación Ciudadela Educativa y Desarrollo Integral, CORCEDIC, Comuna 7 de Barrancabermeja.
} 


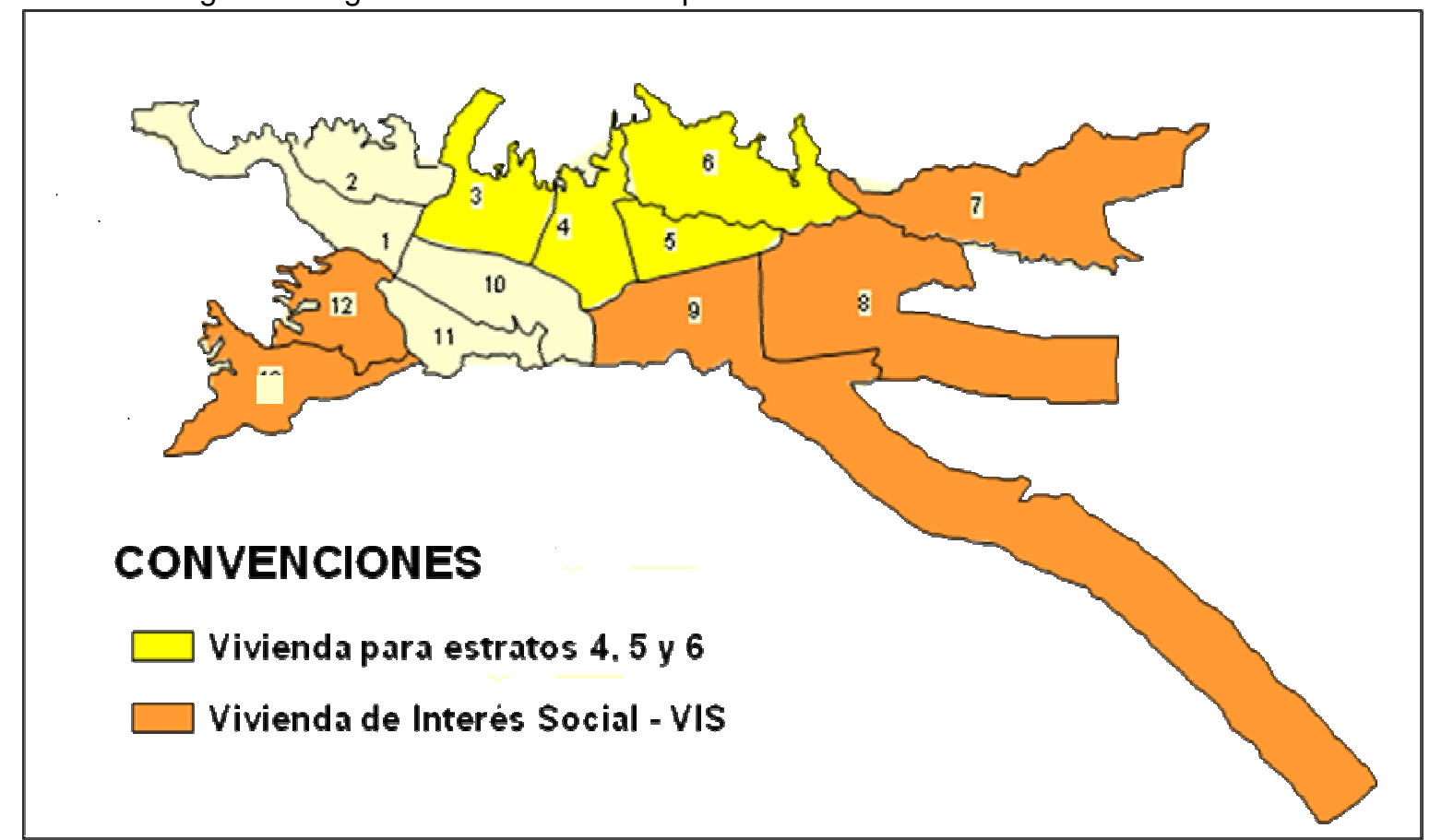

Fuente: Elaboración propia

En el primer caso para obtener la licencia de proyectos urbanísticos de escala micro local ${ }^{11}$; en el segundo caso, para justificar proyectos de renovación o expansión urbana ${ }^{12}$. En este caso podría aplicarse la consigna según la cual bajo el modelo neoliberal el Estado actúa como un facilitador del mercado, o como lo expresa mejor Giraldo:

En términos más simples y por lo tanto más abstractos, entrando en la esencia de la discusión puesta en escena por la ley 388 del 97: sin Estado no mercado y sin éste es imposible el Estado, dos instituciones esenciales de la sociedad que siendo irreductibles, son inseparables: el Estado es quien crea el mercado y éste en la sociedad capitalista, le da sentido de legitimidad al Estado que solo existe en su interrelación por medio y a través del mercado (2006, pág.17).

Incluso en palabras del propio Ministerio de Ambiente, Vivienda y Desarrollo Territorial, los planes parciales tienen un rol funcional al mercado de tierras más que a la intencionalidad de un ordenamiento urbano integral. Así se desprende de las palabras de la Ministra ${ }^{13}$ :

\footnotetext{
${ }_{11}^{11}$ En Ibagué, entidades como la Caja de Compensación Familiar COMFENALCO.

${ }^{12}$ En Ibagué, Planes parciales en el sector Picaleña; en Barrancabermeja, Plan Parcial de Renovación Urbana de la Comuna 1, Sector Comercial.

${ }^{13}$ Presidencia de la República de Colombia. Recuperado el 2 de marzo de 2007. http://www.presidencia.gov.co/sne/2006/febrero/08/02082006.htm
} 
Adicionalmente, el Ministerio de Ambiente, Vivienda y Desarrollo Territorial anunció que el Gobierno trabaja en la reglamentación de los planes parciales, que presentan problemas en varias zonas del país.

Los planes parciales son los instrumentos por los cuales se desarrollan y complementan las disposiciones de los planes de ordenamiento territorial (POT), para áreas determinadas del suelo urbano o del suelo de expansión urbana.

Según la ministra del ramo, Sandra Suárez Pérez, hay muchas ciudades en las cuales ya no hay donde hacer vivienda en suelo urbano, como Bucaramanga y Manizales, ciudades en las que prácticamente ya no hay suelo urbano.

Pero además hay problemas de parte de los municipios del país en cuanto a normas y trámites que obstaculizan el desarrollo de la vivienda social, dijo.

Y agregó: También encontramos otros problemas como que el suelo urbano, así como el de expansión, debe tener unas características particulares. Sin embargo, en muchos municipios se otorgan, sin norma y sin reglamentación, licencias de parcelación en suelo rural, y de esta forma se convierte el suelo en vulnerable, poniendo en riesgo el tema del suelo agrícola y el de los recursos de recursos naturales.

Dijo que también se dan casos de regiones del país donde se están buscando unos desarrollos grandísimos de tipo urbano y donde no está claro, por ejemplo, temas como el de abastecimiento de agua. Por eso se han venido tomando unas medidas y se van a tomar otras, indicó la Ministra.

Entre estas medidas figura la reglamentación en curaduría, construcción de vivienda en suelo agrícola y planes parciales, así como la continuación del acompañamiento y asesoría a los municipios que todavía no han concluido sus planes de ordenamiento territorial POT. Al inicio del actual Gobierno, 414 municipios no tenían plan de ordenamiento territorial, y en la actualidad sólo faltan 57 municipios. El objetivo es que el 100 por ciento de las localidades del país dispongan de POT.

Según el MAVDT (2004, pág. 58) acerca de la formulación y aplicación de la Ley 388 de 1997 se lee:

En agosto de 2002, 5 años después de la expedición de la Ley, 414 municipios no tenían POT adoptado. Por ello el Gobierno se propuso como meta para el año 2006 que todos los municipios de Colombia deberían tener Plan de Ordenamiento Territorial.

Como efecto de ese compromiso asumido por el MAVDT, actualmente el 93\% de los municipios de Colombia (1.022) tienen planes de ordenamiento adoptado. Ello implica que el $97.4 \%$ de la población total del país, el $98.9 \%$ de la población urbana y el 93.8\% de la población rural, cuenten con un instrumento guía que establece los acuerdos para lograr el desarrollo territorial. De otra parte el $88 \%$ del territorio nacional está planificado con visión a largo plazo. 
El documento anuncia una estrategia "...de apoyo y seguimiento a los municipios que han decidido emprender la revisión del Plan, en el marco de lo establecido por la misma Ley 388", pero no se cuenta con información oficial sobre el estado del proceso de revisión, el cual no ha sido asumido con carácter de obligatoriedad por parte de los municipios y frente al cual será necesaria alguna medida de carácter coactivo, tal como ha sido la práctica seguida por las municipalidades para dar cumplimiento a lo ordenado por el legislador.

No es que ya no haya lugar para la vivienda social, como lo percibe la Ministra, más bien la tierra para localizar dicha vivienda ha sido objeto de la creación de una escasez ficticia bajo la figura de los lotes de engorde en los centros geográficos de las ciudades. En consecuencia hay que buscar la tierra para la vivienda social en las periferias urbanas pobres ${ }^{14}$.

Así las cosas, el mercado, en este caso de la tierra urbana, vuelve a colocarse a la altura categorial de una institución. El problema de fondo en la discusión es que al reconocerse tal estatuto, y pese a que la Ley lo establece, su control se torna elusivo y las más de las veces escapa al Estado, su irreductible anverso, capturado por los intereses del capital, expresado en pequeños, medianos y grandes grupos de presión.

A contracorriente de los que consideran la inevitabilidad del modelo neoliberal, el Estado que crea el mercado y que no puede existir sin éste y que a la vez lo legitima, no puede estar por lo tanto al servicio del interés colectivo, pues como una verdad de Perogrullo, su lógica es la lógica del capital, es decir, de la ganancia derivada del plus valor, cualquiera sea el objeto de su realización y la vía o los mecanismos por los cuales se obtiene.

Suficientemente documentado está en los estudios urbanos del pasado y del presente de la sociedad urbanizada, es decir, por excelencia de la sociedad capitalista, que los lugares que adquieren dinámicas generadoras de especulación en los precios de la tierra, empiezan a ser incómodos los asentamientos socioeconómicamente pobres y las actividades que puedan afectar la valorización de los bienes físicos y el ambiente de los mismos.

Así, los espacios urbanos han sido objeto de incesantes e inacabados procesos de renovación, presentados con los más diversos y disímiles adjetivos por parte de agentes inmobiliarios, el sector inversionista privado y el propio gobierno. La renovación urbana no es un asunto nuevo, como quiere hacérselo parecer, a propósito de la aplicación de la Ley 388 de 1997 en Colombia. La modernización urbana en todas las ciudades colombianas durante las décadas 30 a 50 fue en conjunto un gigantesco movimiento de renovación urbana, contenido en algunas ciudades durante la década del 60 pero reiniciado de manera mucho más clara y agresiva en los 70, luego que entraran en vigencia las recomendaciones urbanísticas de Currie y la avalancha de recomendaciones de los organismos multilaterales internacionales, ante la inexorable urbanización de las sociedades latinoamericanas.

En Bogotá buscad a los desplazados por las grandes avenidas en los barrios populares de Ciudad Bolívar, del occidente y del nororiente; en Medellín en las comunas nororientales, en Bello y en Itagüi; en Cali en Aguablanca; en Barranquilla en los barrios bajos del sur cercanos al río Magdalena; en Ibagué en las Comunas 7, 8 y 9, en los lugares más apartados del centro de la ciudad.

\footnotetext{
${ }^{14} \mathrm{Y}$ aclaramos que son periferias urbanas pobres, pues existen las periferias exclusivas, construidas por el capital urbanizador.
} 
Como en una fórmula matemática, con algoritmo y todo, buscad a los más pobres en los lugares justamente opuestos a los lugares donde hoy florece el mercado de la renta del suelo urbano.

El documento del MAVDT y otros (2004, pág. 68). Los resultados perceptibles de la puesta en práctica, expresa:

\subsection{Mejora en los resultados fiscales y económicos.}

A partir de la expedición de los planes de ordenamiento por parte de los municipios, se iniciaron las aplicaciones de los instrumentos que permiten intercambiar norma urbanística de edificabilidad por espacios públicos y servicios urbanos. Más recientemente, se han comenzado a expedir varios estatutos de plusvalía con los cuales los municipios captan para sí parte de las rentas que genera el desarrollo urbano, pudiéndolos aplicar por mandato de la Ley 388 de 1997 a la solución de los problemas de hábitat popular: dotación de agua y saneamiento básico para los más pobres, mejoramiento integral de barrios, y construcción de vivienda popular.

Igualmente, los municipios han iniciado el estudio de comportamiento de impuesto predial y la contribución por valorización. En el caso de los municipios localizados en el departamento de Cundinamarca la Gobernación realizó un apoyo técnico que produjo un cambio en la base gravable, una actualización de la información catastral, todo lo cual, generó un aumento significativo en los ingresos municipales.

Sin duda tales resultados son obvios y sus repercusiones derivarían en notables procesos de reinversión social, con altas tasas de retorno para la comunidad que ha generado la valorización de la tierra urbana, pero no funciona así el mecanismo del reparto de cargas y beneficios: en Colombia se ha ido acuñando una sentencia según la cual las cargas en el proceso reordenador son para los afectados y los beneficios para los realizadores del proceso, es decir, para los inversionistas en finca raíz, en construcción y en el capital financiero de los mismos proyectos; por supuesto, también para los políticos y técnicos corruptos que hacen bien su papel de facilitadores de este nuevo rol del Estado.

\section{La frustración del idealismo planificador y el despilfarro técnico en el ordenamiento territorial}

Como una tempestad, de las que recurrentemente abaten el campo técnico y académico colombiano de tiempo en tiempo, llegó la Ley 388 de 1997, convirtiendo en obligatorio el ejercicio de formular los planes y esquemas de ordenamiento territorial y de paso, dejando en evidencia una vez más, la ausencia de políticas nacionales de Estado. De esta manera, como se ha venido advirtiendo desde la expedición misma de la citada Ley, una ley estatutaria ocupó el lugar de una orgánica, imponiéndose entonces el dicho según el cual en vez de nada algo es algo o pior es nada, que guían bajo una desastrosa influencia filosófica del actualismo y del presentismo existencialistas, los asuntos más serios de la política y la acción del Estado.

Para la mayoría de los apologistas del espíritu de la ley, entre los que desfilan, desde conversos intelectuales poseídos por el hada del discurso de la nueva jerga neoliberal del actuar propositivamente, hasta los técnicos acuciosos de hallar oficio, la promulgación de la Ley 388 era la oportunidad soñada de hacer un verdadero despliegue de toda la tecnología de los diseños asistidos por computador (CAD) y de los sistemas de información geográfica (SIG), aunque no se precisara previamente su aplicabilidad ni sus exigencias técnicas de soporte ni mucho las capacidades humanas para su operación. 
Y así, sin un patrón base, que debía suministrar como obligación de Estado el IGAC, antes de colocar por delante las ansias recaudadoras de su nueva concepción empresarial, consultores, asesores, instituciones públicas y privadas, fueron despachadas a producir la cartografía temática de los planes y esquemas de ordenamiento territorial, cuyas memorias técnicas, sin desconocer excepciones, no pasan de ser un réplica sin mejora, aunque ciertamente más densas y técnicamente almibaradas, de las que para similar efecto han tenido los planes de desarrollo o los planes de manejo de cuencas hidrográficas.

Como se ha advertido en diferentes eventos nacionales sobre el asunto ${ }^{15}$, el ejercicio fue confiado a consultores y asesores ante el desmantelamiento de las Secretarías de Planeación Municipal y Departamental, y por supuesto, ante la clara incapacidad de las municipalidades para responder por esta obligación. Como resultado, hoy plenamente reconocido, la inmensa mayoría de los municipios, incluyendo capitales departamentales, no cuentan con la capacidad ni humana ni técnica instalada para administrar las bases de datos y la cartografía del ordenamiento territorial.

A esta situación, habría que agregarle las obvias dificultades que la presencia del conflicto interno armado ha tenido en el proceso, además de la intromisión del clientelismo en la selección o adjudicación de los contratos para la formulación de los planes y esquemas de ordenamiento. Tampoco pueden dejarse de lado, las no pocas veces enredadas intervenciones técnicas de algunas corporaciones autónomas ${ }^{16}$, cuya incapacidad e inexperiencia en el asunto las convirtió en factores de atascamiento y obstáculo en vez de facilitadoras competentes del proceso. La corrección de estas situaciones últimas solo fueron comprendidas a partir de 2002, lo cual, como se observa en el caso del Tolima, ha dado como resultado un avance en los procesos retrasados y un cumplimiento mucho mayor al presentado hasta 2001. Aún así, es pertinente preguntarse acerca de la calidad técnica de los productos cartográficos, de la unidad en las metodologías aplicadas para el levantamiento de la información y su veracidad, y sobre la tarea pendiente de transferir la información construida en CAD a un SIG. No hay duda que muchos de los ejercicios realizados terminarán por constituir un despilfarro más de recursos públicos y que, por constatación empírica en algunos municipios, éste deberá volverse a ejecutar. Sigue quedando pendiente igualmente, con qué capacidad humana y tecnológica contarán los municipios para administrar y retroalimentar sus bases de datos y para actualizar la información cartográfica en el futuro.

Con respecto a aspectos vitales del proceso, como la formulación de una visión urbanoregional, resulta claro que ésta aparece difusa y más bien como un intento relacional con respecto a las capitales departamentales y centros metropolitanos de influencia supradepartamental, alimentada artificiosamente en el discurso de conectividad con el mercado exterior para insertar al municipio en la moda de la globalización. Ello por supuesto es comprensible, pues si no se ha logrado precisar la escala regional ni la magnitud de sus procesos, tampoco podría esperarse más al respecto.

\footnotetext{
${ }^{15}$ XVI Congreso Colombiano de Geografía, Cali en 2000; XVII Congreso Colombiano de Geografía, Pasto, 2003.

${ }^{16}$ Un ejemplo a destacar, por su indudable aporte y estímulo al proceso, es el de la Corporación Autónoma Regional del Alto Magdalena CAM, que en estrecho trabajo interinstitucional con el Departamento Administrativo de Planeación de la Gobernación y otras entidades del orden departamental, lograron que la totalidad de los 37 municipios de este departamento cumplieran durante el año 2000 con la formulación de sus respectivos planes y esquemas. En este caso el apoyo central estuvo en una adecuada programación, acompañamiento y seguimiento al proceso, pese a que éste fue contratado con consultores particulares. Casos contrarios pueden registrarse durante los primeros cinco años del proceso en departamentos como Bolívar, Santander y Tolima, para citar solo algunos.
} 
Algo similar ocurre con temáticas como el manejo de áreas de especial significación ambiental, tales como parques naturales, ecosistemas estratégicos, cuencas hidrográficas y áreas arqueológicas compartidas, frente a las cuales se encuentra dificultad manifiesta al proponer acuerdos intermunicipales o políticas públicas con posible impacto regional.

En este campo, la limitada definición de lo estratégico deja por fuera la consideración de ecosistemas que siendo de importancia estrictamente municipal, o incluso corregimiental, veredal o urbano, resultan fundamentales a la hora de prever el futuro del ambiente local.

Es el caso, por cierto abundante en Colombia, de sistemas de sierras, sistemas residuales sedimentarios sobre valles interandinos, de las llanuras orientales, de la selva amazónica y pacífica, pero también de los llamados cerros testigos o tutelares, en los cuales se encuentran riquezas no desestimables de biodiversidad para un municipio o sector de éste. Como suele ocurrir con la copia sin beneficio de inventario de la terminología usada por las agencias del Estado en materia ambiental, lo aquí llamado estratégico hace alusión estricta a los grandes sistemas cordilleranos de altura, dejando por fuera la observación rigurosa de nuestra propia realidad socioambiental. 


\section{BIBLIOGRAFÍA}

Giraldo, Fabio. Ciudad y habitat. En: Ministerio de Ambiente Vivienda y Desarrollo Territorial MAVDT, Organización de la Naciones Unidas ONU Hábitat, Metrovivienda, Fedevivienda y Escuela Superior de administración Pública ESAP (2006), Formulación y aplicación de la Ley 388 de 1997 en Colombia: una práctica colectiva hecha realidad. Bogotá: Produmedios, 2006.

Documentos técnicos consultados:

Alcaldía de Ibagué. Plan de Ordenamiento territorial del municipio de Ibagué Tolima, Documento Diagnóstico. Ibagué, 2004.

Contraloría Departamental del Huila. Informe Financiero y de Gestión 2004. Neiva.

Ministerio del Medio Ambiente, Vivienda y Desarrollo Territorial. Estado de los planes de ordenamiento territorial en Colombia. Bogotá, 2004

Legislación colombiana consultada:

Gobernación del Huila. Asamblea Departamental. Ordenanza 78 de 2000. Por medio del cual se adopta el Plan de Ordenamiento Departamental.

Ministerio de hacienda y crédito público, Instituto Geográfico Agustín Codazzi, Resolución 2555 de septiembre 28 de 1998, por la cual se reglamenta la formación actualización d ela formación y conservación del catastro nacional, y subroga la resolución número 660 del 30 de marzo de 1984.

República de Colombia, Congreso de la república. Ley 388 de 18 de julio de 1997, por la cual se modifica la Ley 9 de 1989 y se dictan otras disposiciones.

República de Colombia, Congreso de la república. Ley 617 de 6 de octubre de 2000, por la cual se reforma parcialmente la Ley 136 de 1994, el Decreto Extraordinario 1222 de 1986, se adiciona la Ley Orgánica de Presupuesto, el Decreto 1421 de 1993, se dictan otras normas tendientes a fortalecer la descentralización, y se dictan normas para la racionalización del gasto público nacional.

República de Colombia, Congreso de la república. Ley 550 de 30 de diciembre de 1999, por la cual se establece un régimen que promueva y facilite la reactivación empresarial y la reestructuración de los entes territoriales para asegurar la función social de las empresas y lograr el desarrollo armónico de las regiones y se dictan disposiciones para armonizar el régimen legal vigente con las normas de esta ley.

Recursos de internet consultados

Corporación Autónoma Regional del Alto Magdalena. Informe de Gestión 2005. Recuperado 10 de julio de 2007.

http://www.cam.gov.co/camh/cam/index.php?option=com_content\&task=view\&id=155\&ltemid=2 63.

Departamento Administrativo Nacional de Estadística DANE. Sistema de consulta REDATAM. Recuperado 12 de junio, 2007, de http://190.25.231.242/cgibin/RpWebEngine.exe/PortalAction?\&MODE=MAIN\&BASE=CG2005B ASICO\&MAIN=WebServerMain.inl 
Gutiérrez, Oscar. Revistas del centro de estudios del trabajo Deslinde. Recuperado Abril 15, 2008, de http://www.deslinde.org.co/Dsl41/Dsl41_indice.html

Periódico El País. Recuperado 14 de abril, 2008, de http://www.elpais.com.co/paisonline/ediciones_anteriores/ediciones.php?p=/historico/abr14200 8/PRI

Polanía, Jennifer. Periódico La Nación. Neiva: Una década de transformación urbana. Recuperado 10 de Junio, 2007, de http://www.lanacion.com.co/cms/index.php?option=com_content\&task=blogcategory\&id=77\&lte mid=89\&yearlD=2004\&month $\mid \mathrm{D}=6 \&$ day $I \mathrm{D}=15$

Presidencia de la República de Colombia. FONVIVIENDA ayudará a que 8 mil hogares pobres accedan a casa propia. Recuperado 2 de Marzo, 2007, de http://www.presidencia.gov.co/sne/2006/febrero/08/02082006.htm 
Architecture, City, and Environment

Arquitectura, Ciudad y Entorno 